\title{
Oxytocin increases thresholds of colonic visceral perception in patients with irritable bowel syndrome
}

\author{
D Louvel, M Delvaux, A Felez, J Fioramonti, L Bueno, Y Lazorthes, J Frexinos
}

\begin{abstract}
Aim-The effects of oxytocin on colonic perception of intraluminal distension were evaluated in 26 patients with irritable bowel syndrome (IBS), using a flaccid bag placed in the descending colon and connected to a computerised barostat.

Method-Symptomatic responses (first sensation and pain) were evaluated during isobaric distensions (4 $\mathrm{mm} \mathrm{Hg}$ increments, five minute duration, five minute interval with return to zero pressure between each step), performed automatically by the barostat, during a continuous infusion of placebo or various doses of oxytocin $(10,20,30$, and $50 \mathrm{mU} / \mathrm{min})$.

Results-The distension pressure (mean (SD)) required to induce a first abdominal sensation was $17 \cdot 3(5 \cdot 5) \mathrm{mm} \mathrm{Hg}$ on placebo, $19.9(5.8)$ on oxytocin $10 \mathrm{mU} / \mathrm{min}$ (NS), $22 \cdot 3(6 \cdot 0) \mathrm{mm} \mathrm{Hg}$ on oxytocin 20 $\mathrm{mU} / \mathrm{min}(\mathrm{p}<0.01), 23.1(6.6) \mathrm{mm} \mathrm{Hg}$ on oxytocin $30 \mathrm{mU} / \mathrm{min}(p<0.01)$, and 24.0 (7.1) $\mathrm{mm} \mathrm{Hg}$ on oxytocin $50 \mathrm{mU} / \mathrm{min}$ $(p<0.01)$. The distension pressure required to induce pain was $24.8(6 \cdot 3)$ $\mathrm{mm} \mathrm{Hg}$ on placebo, $26 \cdot 0(5 \cdot 8)$ on oxytocin $10 \mathrm{mU} / \mathrm{min}$ (NS), $33.3(7.8) \mathrm{mm} \mathrm{Hg}$ on oxytocin $20 \mathrm{mU} / \mathrm{min}(\mathrm{p}<0.01), 34 \cdot 2(7 \cdot 6)$ $\mathrm{mm} \mathrm{Hg}$ on oxytocin $30 \mathrm{mU} / \mathrm{min}$ (p<0.01), and $34.3(7.9) \mathrm{mm} \mathrm{Hg}$ on oxytocin $50 \mathrm{mU} /$ $\min (\mathbf{p}<0.01)$. Compliance curves were not different after placebo and oxytocin injection at the different doses. Naloxone did not inhibit the effect of oxytocin. Oxytocin also did not alter somatic perception, characterised by the RIII reflex at the level of the biceps femori.

Conclusion-Oxytocin significantly increases thresholds for visceral perception in IBS patients at doses equal or to greater than $20 \mathrm{mU} / \mathrm{min}$, possibly by acting at the level of visceral afferents.

(Gut 1996; 39: 741-747)
\end{abstract}

Keywords: colonic distension, irritable bowel syndrome, viscerosensitivity, barostat, colonic tone, visceral thresholds, oxytocin.

The pathophysiology of irritable bowel syndrome (IBS) remains largely unknown. A variety of motility disorders have been described but there is no consensus regarding changes in colonic motility under basal conditions, ${ }^{1} 2$ during emotional stress, ${ }^{3-5}$ after a meal, ${ }^{167}$ or in response to pharmacological stimulation. ${ }^{6} 8$ It has become apparent that an abnormally decreased threshold for visceral sensitivity may also play an important part in the pathophysiology of IBS. Previous studies in humans have found lowered visceral sensory thresholds during intraluminal distension of the oesophagus in patients with non-cardiac chest pain ${ }^{9} 10$ and of the stomach in patients with functional dyspepsia. ${ }^{11} 12$ Similar hypersensitivity to distension has also been reported for the colon in IBS patients. ${ }^{13-18}$

Besides opioid peptides, several neuropeptides play an important part as mediators of the antinociceptive pathways: vasopressin, substance $P$, and neurotensin. ${ }^{19}$ It has been recently shown that somatostatin may decrease abdominal symptoms in patients with IBS, increasing visceral sensory thresholds in the colon, up to the level of controls, without modifying pressure-volume relation (compliance).$^{20}$ It is well known that oxytocin is widely distributed in many areas of the central nervous system and the spinal cord. ${ }^{21}$ Its effects include both hormonal and neuronal processes. Among the latest, oxytocin may modify behaviour of learning and memory. Oxytocin given intraperitoneally as well as intracisternally to rodents exerts an antinociceptive action. ${ }^{22}{ }^{23}$ In a patient with opiate resistant cancer pain, the injection of oxytocin into the third ventricle was reported to result in effective analgesia. ${ }^{24} 25$ On the other hand, animal studies have shown that the analgesic effect of oxytocin could be opiate mediated. ${ }^{22}$

Consequently the aim of this study was to investigate the effects of oxytocin on thresholds of visceral perception and pain sensation during isobaric colonic distensions in IBS patients, using a computerised barostat and to investigate a possible mediation of these effects by an opioid pathway. In addition, we analysed the effects of an effective dose of oxytocin on somatic perception thresholds, as characterised by the RIII cutaneous reflex.

\section{Methods}

PATIENTS

Twenty six patients (15 men) were included. Their mean age was 45 years (range 24-63). All patients had a clinical diagnosis of IBS, based on the Rome criteria ${ }^{26}$ : they presented with abdominal pain at least three times a week and constipation ( $\leq 3$ bowel movements per week). Patients gave informed consent to participate in the experimental procedures that 
had been approved beforehand by the Institutional Ethical Board.

All patients were required to have a normal physical examination and a normal colonoscopy (to eliminate an organic disease) before acceptance in the study and none were taking medication other than oral contraceptives, at least 15 days before the study. All women were negative for $\beta-\mathrm{HCG}$ blood test. Patients were admitted to the clinical research unit the day before the study and were prepared by ingesting four litres of polyethyleneglycol 4000. Bowel cleansing was completed by repeated tap water enemas until all faecal effluent was clear fluid, free of any particulate matter.

\section{RECORDING ASSEMBLY}

\section{Barostat}

The device (Barostat INRA, Toulouse, France) consisted of a sensitive pressure transducer (range 0-80 $\mathrm{mm} \mathrm{Hg}$, SCXOIDN, Sensym, 91 Savigny sur Orge, France) coupled through a computer (32 Kbytes ROM, 32 Kbytes RAM, 80C32, Intel, 78 St Quentin en Yvelines, France) and a stepping motor to a bellows with a reservoir capacity of $600 \mathrm{ml} .^{27}$ The system could be activated with a lag time of $10 \mathrm{~ms}$ and the maximal air flow was $30 \mathrm{ml} / \mathrm{s}$. The volume of air inside the bag was determined electronically by the computer from the known excursion of the bellows within the

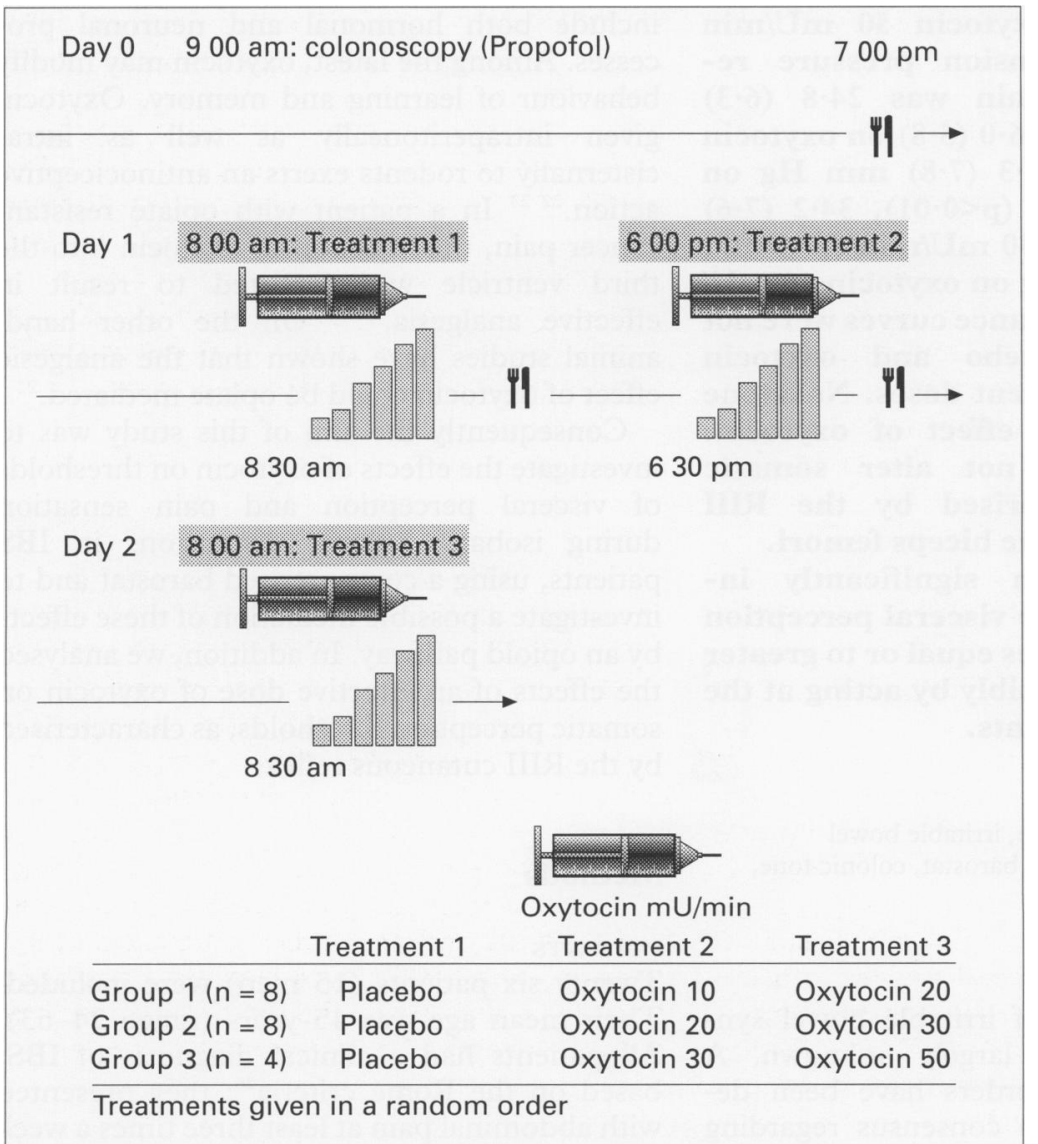

Figure 1: Design of the distension part of the protocol. After placement of the probe, patients underwent three distension sessions with random administration of treatments, either placebo or two consecutive doses of oxytocin. reservoir system. The barostat apparatus included a built in computer system that could be programmed to automatically perform distensions with fixed time lag (five minute duration, five minute interval with return to baseline volume between each successive increment) and bag pressure increments (4 $\mathrm{mm} \mathrm{Hg}$ increments). Distensions could therefore be performed by completely deflating the bag between each pressure increment.

\section{Colonic probe}

A single lumen silicone tube ( $8 \mathrm{~mm}$ diameter, Silastic, Dow Corning, Midland, MI, USA) was assembled so that the lumen was located within the barostat bag and the open end of the tube connected to the output of the bellows chamber. A thin wall polyethylene bag $(40 \mu \mathrm{m}$ thick) was fastened tightly to the tube. The maximal capacity of the bag (during table top inflation) was $500 \mathrm{ml}$ with a maximal length of $10 \mathrm{~cm}$. Before each experiment, the barostat bag was checked for air leaks at a pressure of $20 \mathrm{~mm} \mathrm{Hg}$ maintained during 15 minutes. Within the range of volumes used in our study, the barostat bag compliance was considered infinite. ${ }^{18}$

\section{CONDUCT OF THE STUDY}

\section{Effect of oxytocin on sensory thresholds and dose response relation}

Selected patients presented to the endoscopic unit after a 12 hour fast and adequate bowel preparation. Colonoscopy was performed on day 0 (D0) at 900 am with the patients in the left lateral position using minimal air insufflation. Colonoscopy was performed to the caecum in all patients and no retained particulate matter was observed in any case. Premedication included intravenous propofol (2 $\mathrm{mg} / \mathrm{kg}$ ) (ICI Pharma, Cergy, France), under surveillance of an anaesthetist. A thread attached to the tip of the colonic probes was used to pull it up into the colon alongside the colonoscope (CFV10, Olympus, Tokyo, Japan), by using a biopsy forceps to carry it. The barostat bag was positioned in the descending colon. Patients were then transported to a recovery room where they were allowed to rest. All experimental procedures began on day 1 (D1) to permit full recovery from anaesthesia. Positions of the colonic probe and barostat bag were verified fluoroscopically before and after experimental procedures. Patients were requested to remain in a $30^{\circ}$ supine position during the entire recording sessions.

The barostat bag was used to perform intracolonic isobaric distensions at $830 \mathrm{am}$ and $600 \mathrm{pm}$ on day 1 and 830 on day 2 (Fig 1). Twenty patients received, in a random order, a continuous infusion of placebo (saline solution) or two doses of oxytocin $(10 \mathrm{mU} /$ min: $\mathrm{n}=8,20 \mathrm{mU} / \mathrm{min}: \mathrm{n}=16,30 \mathrm{mU} / \mathrm{min}$ : $\mathrm{n}=12,50 \mathrm{mU} / \mathrm{min}: \mathrm{n}=4$ ), starting 30 minutes before the distension session began and maintained constant during the whole distension 
session. Distensions were performed automatically by the computerised barostat to achieve successive increments of $4 \mathrm{~mm} \mathrm{Hg}$ every five minutes preceded by completely deflating the barostat bag during five minutes before the next distension, until pain threshold was obtained. The average duration of distension experiments on placebo could be estimated at 60 to 70 minutes from the previous studies performed with this distension protocol in our laboratory. ${ }^{1820}$ Using a standardised visceral perception questionnaire, patients were requested to indicate when they first felt an abdominal sensation (threshold of first perception) and then when they first felt a sensation of abdominal pain (threshold of pain). At the pain threshold or when the maximum pressure of $40 \mathrm{~mm} \mathrm{Hg}$ was reached, the bag was deflated and this completed the experimental procedure.

\section{Effect of naloxon on sensory modulation by oxytocin}

In six patients, the effect of naloxone was tested on the modulation of the sensory thresholds by oxytocin. The barostat bag was used to perform intracolonic isobaric distensions at 830 am and $630 \mathrm{pm}$ on day 1 , according to the same protocol as described above (Fig 1). Each patient received a continuous infusion of oxytocin $(30 \mathrm{mU} / \mathrm{min})$, starting at 800 am and $600 \mathrm{pm}$ - that is, 30 minutes before the beginning of the distension session. At $815 \mathrm{am}$ and $615 \mathrm{pm}$ on D1 each patient received in a random order an intravenous injection of placebo ( $5 \mathrm{ml}$ saline solution) or naloxone $(0.4$ $\mathrm{mg}$ diluted in $5 \mathrm{ml}$ saline solution). Then the distension was performed.

\section{EVALUATION OF SOMATIC PERCEPTION BY THE} RIII REFLEX

Somatic perception was evaluated in 12 patients who participated in other parts of the study. Forty eight hour washout periods were systematically observed between the two trials.

The method for stimulating the sural nerve and recording the RIII reflex activity from biceps femoris was similar to that used in other studies. ${ }^{28} 29$ The sural nerve was stimulated behind the lateral malleolus through a pair of surface electrodes on skin covered with cream. The electrical stimulus was delivered by a constant intensity stimulator and consisted of a $20 \mathrm{~ms}$ train of six rectangular pulses $(1 \mathrm{~ms}$ duration each). A warning signal predicted the stimulation. The time interval between two successive stimulations varied with an approximate mean interval of 10 seconds. Reflexes responses were recorded from the ipsilateral biceps femoris muscle using a pair of surface electrodes on the skin overlying the muscle. The latency of a reflex activity corresponding to a RIII response ranged from 90 to $180 \mathrm{~ms}$. The response was considered present when the amplitude of the electrical signal was greater than $50 \mu \mathrm{V}$. The calculation used to define the threshold stimulus inducing a RIII reflex was based upon the frequency of occurrence of this
RIIII reflex ${ }^{2829}$ rather than on the $10 \%$ RIII maximal amplitude. ${ }^{30}$ The frequency of occurrence of the RIII response was calculated for each intensity level.

After an initial sequence of stimulus performed within treatment and a recovery period of 45 minutes, an infusion of oxytocin $(30 \mathrm{mU} /$ $\mathrm{min}$ ) was given to six patients and placebo to the six others, in a random order, as described for distension studies. Thirty minutes later, a new sequence of stimuli was applied and the RIII threshold measured.

\section{DATA ANALYSIS}

Pressure and volume of the barostat bag were simultaneously recorded on a potentiometric recorder (BS 270, Gould, Paris, France) for later visual analysis, to permit comparison of pressure-volume curves on placebo and on the different doses of oxytocin. Visceral perception thresholds were characterised by the pressure of inflation of the barostat bag triggering a definite abdominal sensation. All values were expressed as mean (SD). Statistical analysis was performed by a non-parametric paired test when comparing the sensory thresholds on placebo and oxytocin. Pressure-volume curves were compared using the analysis of variance (two way ANOVA).

The influence of treatment on the sensory perception of colonic distension was also evaluated by comparing the number of subjects in whom a sensation was elicited at a certain level of distension. The cumulative number of patients taking placebo and the various doses of oxytocin were compared by the $\chi^{2}$ test, with Bonferroni's correction, for each step of distension.

Although the treatment sequences were carefully randomised between subjects, we further tested the possibility of a carry over effect of repeated distensions, using a fully factorial (m)ANOVA to test the influence of order of distension, treatment, and interaction of both on the sensory thresholds. All $\mathrm{p}$ values $<0.05$ were considered significant in this study.

\section{Results}

TOLERANCE OF THE PROBE AND TECHNICAL ASPECTS OF RECORDING SESSIONS

A total of 26 patients were included in this study. Placements of probes under colonoscopy was not responsible for any complication. In each patient, the duration of the experiments including distensions never exceeded a 36 hour recording. The probe was well tolerated in all patients: diarrhoea, urgent bowel movement or probe migration did not occur. At the end of the recording session, the position of the probe was checked on a plain film of the abdomen. The tip of the probe was still in the descending colon in all patients.

TOLERANCE OF OXYTOCIN INFUSION No side effect was seen during or after intravenous infusion of oxytocin at doses ranging 


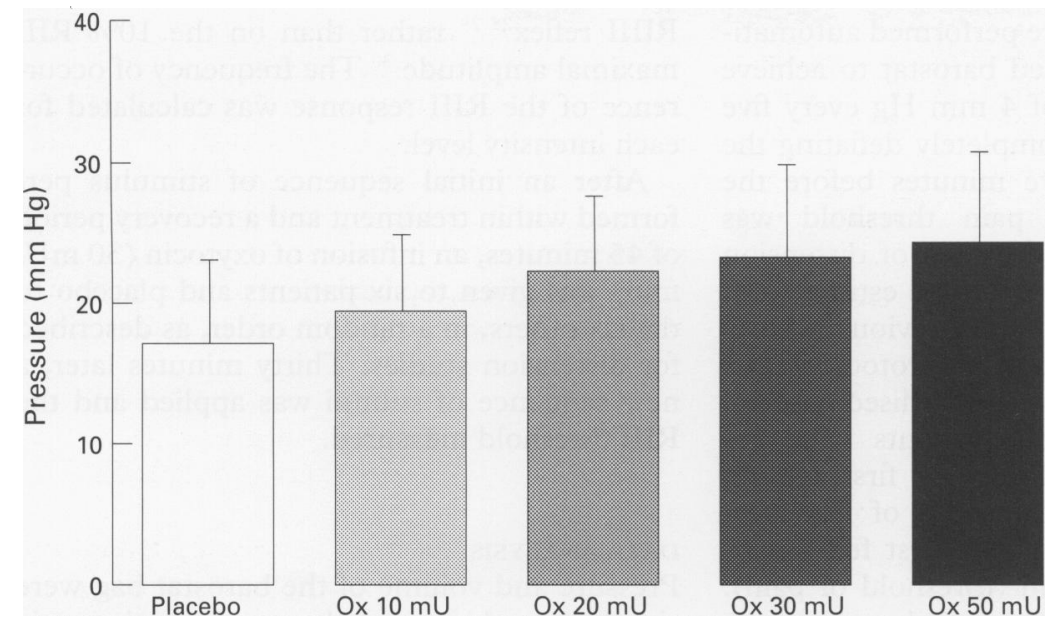

Figure 2: Mean barostat bag pressure at the first sensation threshold in IBS patients taking placebo and the various doses of oxytocin $(O x)(10,20,30$, and $50 \mathrm{mU} / \mathrm{min})$. Oxytocin at $10 \mathrm{mU} / \mathrm{min}$ had no effect on visceral perception. The mean bag pressure required to induce visceral perception was significantly increased after oxytocin $(20,30$, and $50 \mathrm{mU} / \mathrm{min})$ $(p<0 \cdot 01)$.
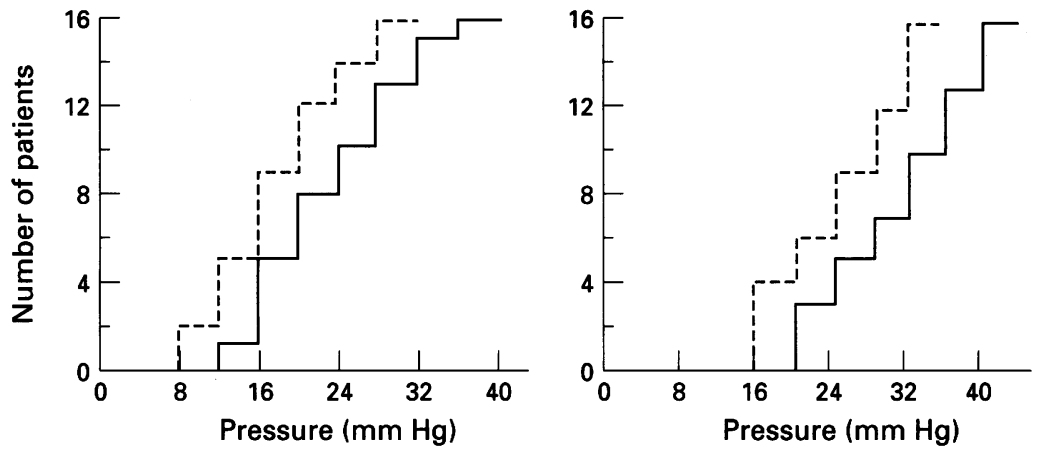

Figure 3: Cumulative number of patients who experienced a first abdominal sensation (left panel) or pain (right panel) during isobaric colonic distension with placebo (dotted line) or oxytocin at the dose of $20 \mathrm{mU} / \mathrm{min}$ (plain line). The curves for IBS patients receiving oxytocin show a significant shift toward higher pressures compared with placebo ( $\chi^{2}$ test; $p<0 \cdot 001$ ).

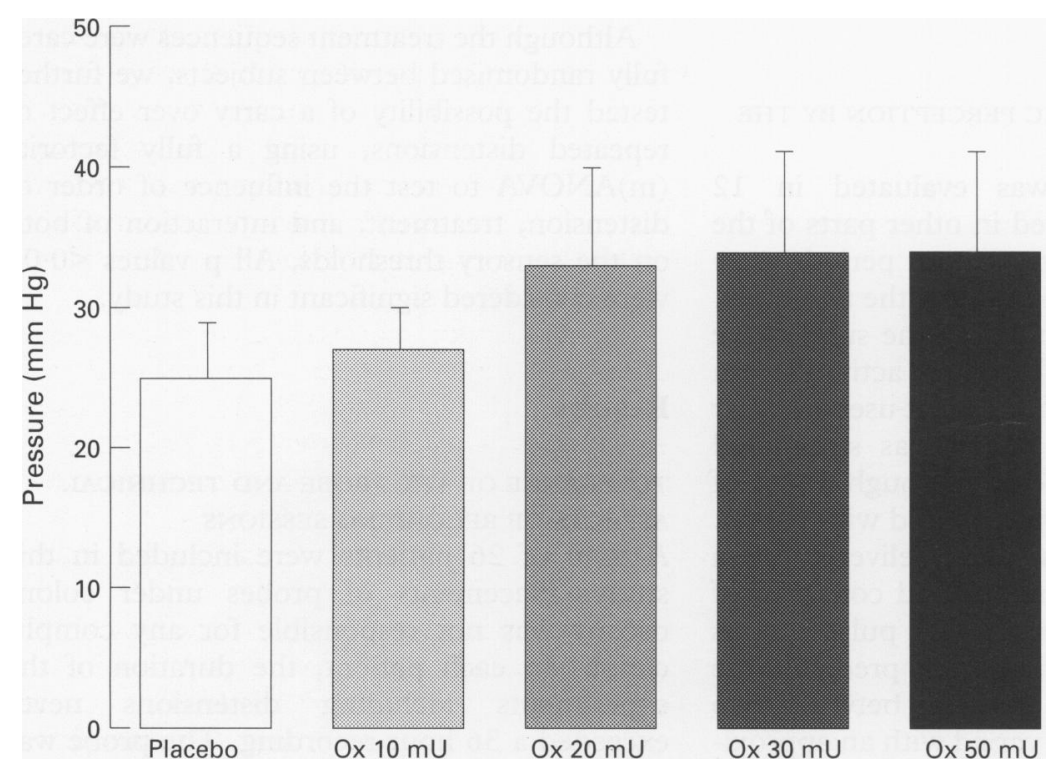

Figure 4: Mean barostat bag pressure at the pain threshold in IBS patients taking placebo and the various doses of oxytocin $(O x)(10,20,30$, and $50 \mathrm{mU} / \mathrm{min})$. Oxytocin at $10 \mathrm{mU} / \mathrm{min}$ had no effect on visceral perception. The mean bag pressure required to induce pain was significantly increased after oxytocin $(20,30$, and $50 \mathrm{mU} / \mathrm{min})(p<0.01)$.

from 10 to $30 \mathrm{mU} / \mathrm{min}$. However, during intravenous infusion of oxytocin at the dose of $50 \mathrm{mU} / \mathrm{min}$, four patients experienced moderate headache. This is the reason why this group of patients was limited to four.
EFFECT OF OXYTOCIN ON VISCERAL PERCEPTION IN IBS PATIENTS

\section{First sensation threshold}

The mean (SD) distending pressure inducing a first abdominal sensation was $17 \cdot 3(5 \cdot 5) \mathrm{mm}$ $\mathrm{Hg}$ with placebo (Fig 2). After the infusion of oxytocin at the dose of $10 \mathrm{mU} / \mathrm{min}$, the mean distension pressure inducing a sensation of discomfort was $19.0(5 \cdot 8) \mathrm{mm} \mathrm{Hg}$ (NS versus placebo). With oxytocin, at the dose of 20, 30, and $50 \mathrm{mU} / \mathrm{min}$, there was a significant increase of the mean distending pressure required to induce an abdominal sensation, up to $22.3(6.0) \mathrm{mm} \mathrm{Hg}(20 \mathrm{mU} / \mathrm{min})(\mathrm{p}<0.01)$, $23.1(6.6) \mathrm{mm} \mathrm{Hg}(30 \mathrm{mU} / \mathrm{min})(\mathrm{p}<0.01)$, and $24.0(7.1) \mathrm{mm} \mathrm{Hg}(50 \mathrm{mU} / \mathrm{min})(\mathrm{p}<0.01)$ respectively.

Figure 3 shows the cumulative number of patients experiencing a first abdominal sensation with either placebo or oxytocin at the dose of $20 \mathrm{mU} / \mathrm{min}$ for a given distending pressure. Twelve of 20 patients who received placebo experienced a first sensation at a pressure $\leq 24 \mathrm{~mm} \mathrm{Hg}$. With oxytocin $(20 \mathrm{mU} /$ min) eight of 16 patients experienced discomfort at a pressure $\leq 24 \mathrm{~mm} \mathrm{Hg}(\mathrm{p}<0.001)$. The curves obtained with oxytocin $(20 \mathrm{mU} /$ min) displayed a significant shift towards higher distension pressures when compared with placebo. Furthermore, barostat bag distension up to the pressure of $28 \mathrm{~mm} \mathrm{Hg}$ without inducing an abdominal sensation was possible in three patients after oxytocin (20 $\mathrm{mU} / \mathrm{min}$ ), compared with none after placebo $(\mathrm{p}<0.001)$.

\section{Pain threshold}

During isobaric distensions, the mean distending pressure inducing a sensation of pain was $24.8(6.3) \mathrm{mm} \mathrm{Hg}$ with placebo. After the infusion of oxytocin $(10 \mathrm{mU} / \mathrm{min})$, the mean distension pressure to induce a sensation of pain was $26 \cdot 8(2 \cdot 8) \mathrm{mm} \mathrm{Hg}$ (NS versus $\mathrm{p}$ value) (Fig 4). With oxytocin, at the dose of 20 , 30 , and $50 \mathrm{mU} / \mathrm{min}$, there was a significant increase in the mean distending pressure required to induce a sensation of pain up to $33.3(7.8) \mathrm{mm} \mathrm{Hg}(20 \mathrm{mU} / \mathrm{min})(\mathrm{p}<0.01)$, $34.2(7.6) \mathrm{mm} \mathrm{Hg}(30 \mathrm{mU} / \mathrm{min})(\mathrm{p}<0.01)$, and $34.3(7.9) \mathrm{mm} \mathrm{Hg}(50 \mathrm{mU} / \mathrm{min})(\mathrm{p}<0.01)$ respectively.

Figure 3 shows the cumulative number of patients experiencing a sensation of abdominal pain, with either placebo or oxytocin at the dose of $20 \mathrm{mU} / \mathrm{min}$, for a given distending pressure. With placebo, nine of 20 patients experienced pain at a pressure $\leq 28$ $\mathrm{mm} \mathrm{Hg}$ compared with only seven of 16 patients after oxytocin (20 $\mathrm{mU} / \mathrm{min})$ $(p<0.001)$. The curves obtained with oxytocin at the dose of $20 \mathrm{mU} / \mathrm{min}$ displayed a significant shift towards higher distension pressures when compared with placebo. Furthermore, barostat bag distension up to the pressure of $32 \mathrm{~mm} \mathrm{Hg}$ was possible without inducing a pain sensation in six IBS patients after oxytocin $(20 \mathrm{mU} / \mathrm{min})$ compared with none after placebo $(\mathrm{p}<0.001)$. 
Results of the fully factorial (M) ANOVA of the effects of treatment by oxytocin at the various doses or placebo and order of distension session on the pain threshold

\begin{tabular}{lrrrrr}
\hline & $\begin{array}{l}\text { Sum of } \\
\text { squares }\end{array}$ & DF & $\begin{array}{l}\text { Mean } \\
\text { squares }\end{array}$ & F ratio & $p$ Value \\
\hline Order & 2.849 & 2 & 1.425 & 0.323 & 0.572 \\
Treatment & 311.239 & 4 & 103.746 & 11.752 & 0.001 \\
Interaction & 50.147 & 7 & 7.164 & 0.811 & 0.582 \\
\hline
\end{tabular}

$\mathrm{DF}=$ degrees of freedom.

\section{Exclusion of a carry over effect of repeated distension tests}

To exclude a carry over effect of repeated distension tests, we analysed the influence of the order of distension tests and treatment on the sensory thresholds in a general linear model (Table). No influence of the order was observed, nor any interaction between treatment and order.

EFFECT OF NALOXONE ON MODIFICATIONS OF VISCERAL PERCEPTION INDUCED BY OXYTOCIN (20 MU/MIN)

During isobaric distensions, the mean distending pressure inducing a first sensation was $22.7(6.6) \mathrm{mm} \mathrm{Hg}$ with oxytocin at the dose of $30 \mathrm{mU} / \mathrm{min}$. When naloxone was injected, the mean distending pressure within the barostat bag inducing a first sensation was 22.5 $(7 \cdot 1) \mathrm{mm} \mathrm{Hg}$ (NS versus oxytocin $30 \mathrm{mU} / \mathrm{min}$ alone).

Likewise, the mean distending pressure inducing a sensation of pain was $33 \cdot 1(7 \cdot 2) \mathrm{mm}$ $\mathrm{Hg}$ with oxytocin at the dose of $20 \mathrm{mU} / \mathrm{min}$ and was not affected by injection of naloxone $(33.3(6.9) \mathrm{mm} \mathrm{Hg})$ (NS versus oxytocin 30 $\mathrm{mU} / \mathrm{min}$ alone).

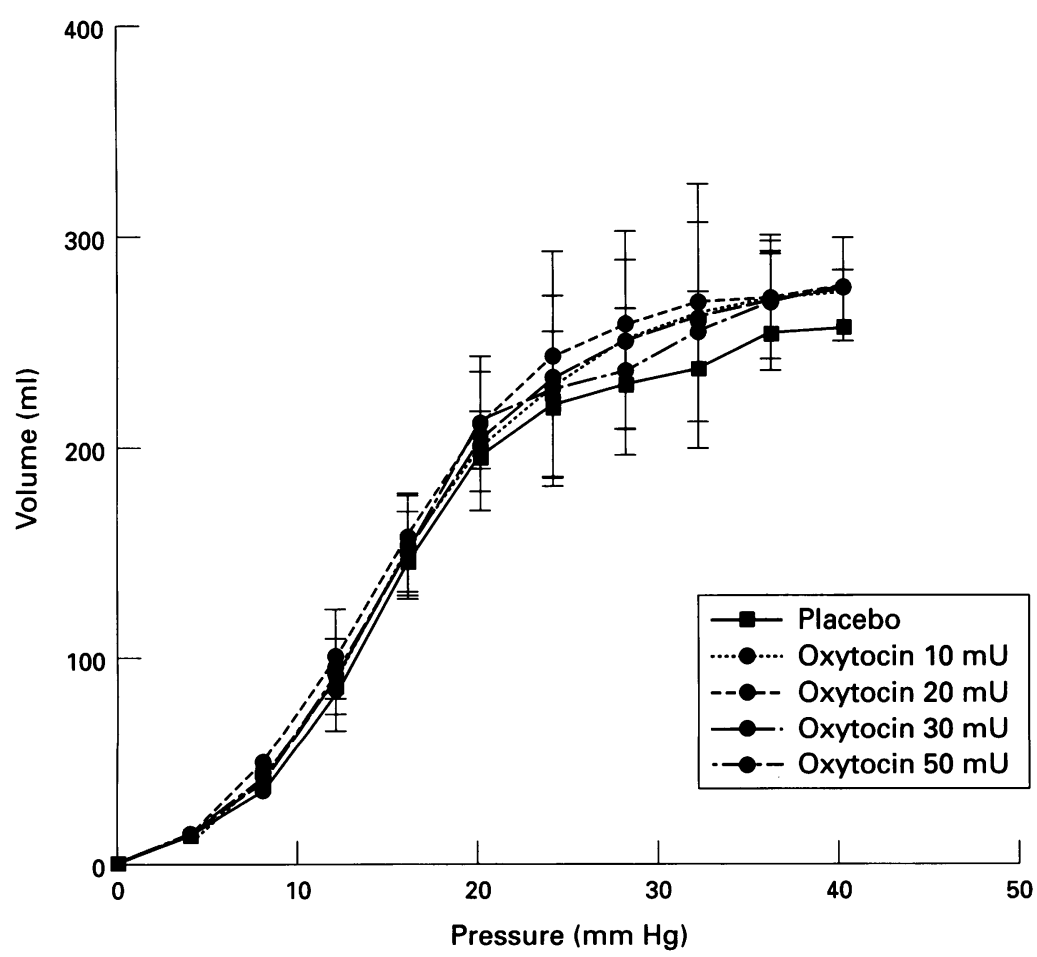

Figure 5: Colonic pressure-volume curves obtained during isobaric distension in IBS patients taking either placebo or oxytocin injection (10,20,30, and $50 \mathrm{mU} / \mathrm{min})$. Curves do not differ significantly (analysis of variance). The slope of these curves was also not different.
PRESSURE-VOLUME RELATION DURING ISOBARIC DISTENSIONS (PLACEBO AND OXYTOCIN)

Pressure-volume curves (compliance curves) were obtained during isobaric distensions after placebo and the different doses of oxytocin. There was no significant difference in the bag volume for a given pressure when comparing distensions with placebo and the different doses of oxytocin (Fig 5).

EFFECT OF OXYTOCIN ON THE SOMATIC PERCEPTION CHARACTERISED BY THE RIII REFLEX

When electrical stimulation was applied on the skin of the leg behind the lateral malleolus, a RIII reflex was recorded at the level of the biceps femoris, for a stimulation of $10.4(1.5)$ $\mathrm{mA}$, with placebo and $11.8(1 \cdot 7) \mathrm{mA}$, with oxytocin $30 \mathrm{mU} / \mathrm{min}$ (NS). The intensity of the response was also not changed by oxytocin.

\section{Discussion}

In this study, we observed that a continuous infusion of oxytocin could increase the sensory thresholds of first perception and pain triggered by a luminal distension of the left colon. This study has been conducted in IBS patients with a characterised visceral hypersensitivity to colonic distension, their sensory thresholds ranging in the pressures previously recorded in another group of IBS patients ${ }^{20}$ and those were significantly lowered compared with controls. IBS patients have also been characterised as hypersensitive in volume scaled distension experiments, using a similar protocol and in comparison with healthy controls. ${ }^{18}$ In these patients with a pronounced hypersensitivity, oxytocin was able to increase the first sensation and the pain thresholds up to those observed in the control group of our previous study. ${ }^{18}$ Similar results have been obtained previously with the somatostatin analogue octreotide on colonic $^{20}$ and rectal ${ }^{31}$ sensory thresholds or with the $\kappa$ agonist fedotozine on colonic sensory thresholds. ${ }^{32}$

This effect of oxytocin is not the consequence of a modification of the compliance of the colonic wall, as shown by the pressurevolume curves. At all tested doses of oxytocin, these curves were closely similar and their slope was not different. Similarly, octreotide and fedotozine did not change the elastic properties of the rectocolonic wall. ${ }^{18} 203132$ This finding leads to the conclusion that oxytocin could act directly on the nerve afferent pathways to modulate sensory thresholds. In contrast, changes in compliance have been observed with granisetron, a 5HT-3 antagonist acting on sensory thresholds and also on gut compliance and colonic transit. ${ }^{33} 34$ The effects of oxytocin on gut motility have been poorly investigated so far. In rats, oxytocin does not delay gastric emptying during the lactation period. ${ }^{35}$ In another study, oxytocin injected in the vagus dorsal motor nucleus decreased gastric motility and tone, thereby mimicking the action of the paraventricular nucleus on gastric motility. ${ }^{36}$ The 
actions are mediated through the central nervous system.

Oxytocin could thus also act as an analgesic at either the central or peripheral levels to modulate perception of nociceptive sensations. Systemic or intracerebral injection of vasopressin has been reported to produce antinociception in rodents. ${ }^{37}{ }^{38}$ Oxytocin given intraperitoneally ${ }^{22}$ as well as intracisternally ${ }^{22}{ }^{23}$ has an antinociceptive effect in rodents and could be a potential analgesic agent. The antinociceptive effect of oxytocin occurs through the activation of oxytocin receptors because the intracerebroventricular injection of the oxytocin antagonist $\mathrm{d}\left(\mathrm{CH}_{2}\right)_{5}-\mathrm{Tyr}(\mathrm{Me})-\left[\mathrm{Orn}^{8}\right]-$ vasotocin, while having no influence in itself on nociception, completely prevented the antinociceptive effect of an equal dose of oxytocin. ${ }^{39}$ Moreover, intraperitoneal effective doses to obtain an effect on nociception are about 200 times higher in rats than intracerebroventricular ones, indicating that antinociceptive effects of oxytocin could be centrally mediated. ${ }^{39}$ This assumption is reinforced by the finding that in the mouse, an intracerebral injection of the oxytocin receptor antagonist blocks the effect of subcutaneous oxytocin, arguing in favour of the possibility for oxytocin to cross the blood-brain barrier. ${ }^{40}$ In humans, an injection of oxytocin $(300 \mu \mathrm{g})$ into the third ventricule of a patient with intractable pain caused by opiate resistant cancer pain was reported to result in effective analgesia lasting 75 minutes. ${ }^{24} 25$

The analgesic effect of oxytocin on nociceptive perception at a central level is supported by detailed observations on the location of oxytocin in various areas of the brain. It has been established that oxytocin is not confined to the hypothalamicneurohypophyseal tract but is widely distributed in neuronal networks in the central nervous system. ${ }^{21}$ Several authors have located oxytocin and various kinds of neuropeptides in the nucleus tractus solitarii, which is involved in the regulation of afferents of cardiovascular, respiratory, gustatory, and gastrointestinal systems. ${ }^{41}$ Oxytocinergic neurons project from the hypothalamic paraventricular nucleus to many regions in the brain, including areas involved in pain transmission - such as, the periaqueductal gray and the raphe nuclei. ${ }^{22}$

Few studies have, in contrast, evaluated the peripheral role of oxytocin. It is present in neural pathways in the spinal cord, concentrated in superficial layers of the spinal dorsal horns, in particular in the substancia gelatinosa (which is involved in the primary processing nociceptive information), and the intermediolateral column (site of origin of preganglionic sympathetic neurones). ${ }^{37}$ However oxytocin does not seem to have a major role in the nociceptive processes in the lumbosacral spinal cord in the rat. ${ }^{37}$

Oxytocin may thus play the part of a general analgesic. Therefore, we evaluated the effects of an infusion of oxytocin on the somatic perception of a cutaneous electrical stimulation. The level of perception was characterised by the RIII reflex of the biceps femori.
We did not observe any effect of oxytocin in these experimental conditions on somatic perception in IBS patients. Somatic perception is known to be normal in patients with IBS. ${ }^{42}$ This finding allows us to assume that oxytocin does not act through a global analgesic effect and that it could even act only on hypersensitive sensory pathways.

Finally we considered the question of the relation between the endogenous opioid system and oxytocin. This relation has been studied in rats: the antinociceptive effect of oxytocin is prevented by naltrexone and oxytocin causes a small but significant increase in the intensity and duration of the antinociceptive effect of morphine. ${ }^{39}$ However, a minor but still significant part of the antinociceptive effect of oxytocin may be naloxone insensitive. ${ }^{22}$ In mice, the development of acute morphine tolerance and naloxone-precipitated morphine withdrawal symptoms were inhibited by oxytocin after subcutaneous and intracerebroventricular injection. ${ }^{43}$ The same effects were seen after central administration of a specific antioxytocin serum. ${ }^{44}$ In this study, we could not inhibit the effect of oxytocin on colonic sensory thresholds by naloxone, indicating that in IBS patients, oxytocin modulates viscersal hypersensitivity without interacting with enkephalinergic nerves.

In conclusion, oxytocin increases thresholds of visceral sensory perception in IBS patients, through a modulation of the activity of afferent nerve pathways. The exact level of action of oxytocin is not known so far but its action is not related to a global analgesic effect. Oxytocin also does not change colonic compliance and adaptation of the colon to distension. Although a clinical use of oxytocin to treat abdominal pain related to IBS cannot be envisaged, a better understanding of the relation between visceral sensitivity and the hormones acting on the female genital tract could lead to the development of new treatments for IBS patients as shown recently with the report of some clinical benefit of leuprolide in this disorder. ${ }^{4546}$

The authors thank Mr Marcel Caussette and Thierry Hachet for providing the probes and maintaining the barostat. The cooperation of the nurses of the Clinical Unit of Gastroenterology is also appreciated for surveillance of recordings.

1 Buéno L, Fioramonti J, Rukebusch Y, Frexinos J, Coulon P. Evaluation of colonic myoelectric activity in health and in functional disorders. Gut 1985; 21: 480-5.

2 Frexinos J, Fioramonti J, Buéno L. Colonic myoelectrical activity in IBS painless diarrhoea. Gut 1987; 28: 1613-8.

3 Whitehead WE, Engle BJ, Schuster MM. Irritable bowel syndrome: physiological and psychological difference between diarrhea-predominant and constipationpredominant patients. Dig Dis Sci 1980; 35: 404-13.

4 Welgan $P$, Meshkinpour H, Beeler M. Effect of anger on colon motor and myoelectric activity in the irritable bowel syndrome. Gastroenterology 1988; 14: 1150-6.

5 Camilleri M, Neri M. Motility disorders and stress. Dig Dis Sci 1989; 34: 1777-86.

6 Sullivan MA, Cohen S, Snape WJ Jr. Colonic myoelectrical activity in irritable bowel syndrome. Effect of eating and activity in irritable bowel syndrome. Effect of eatin
anticholinergics. $N$ Engl $\Im$ Med 1978; 298: 878-83.

7 Bazzocchi G, Ellis J, Villanueva-Meyer J, Jing J, Reddy SN, Meno I, et al. Postprandial colonic transit and motor activity in chronic constipation. Gastroenterology 1990; 98: $686-93$

8 Snape WJ Jr. Irritable bowel syndrome. In: Cohen S, Soloway RD, eds. Functional disorders of the gastrointestinal tract. New York: Churchill Livingstone, 1987: 69-83. 
9 Richter JE, Barish CF, Castell DO. Abnormal sensory perception in patients with esophageal chest pain. perception in patients with es
Gastroenterology 1986; 91: 845-52.

10 De Caestecker JJ, Pryde A, Hedding RC. Site and mechanism of pain perception with oesophageal balloon distension and intravenous edrophonium in patients with oesophageal chest pain. Gut 1992; 33: 580-6.

11 Bradette M, Paré P. Visceral perception in health and in functional dyspepsia. A cross-over study of gastric distension with placebo and domperidone. Dig Dis Sci 1991; 36: 52-8.

12 Lémann M, Dederding JP, Flourié B, Franchiesseur C, Rambaud JC, Jian R. Abnormal perception of visceral pain in response to gastric distension in chronic idiopathic pain in response to gastric distension in chr. Dig Dis Sci 1991; 36: 1249-54.

13 Ritchie J. Pain from distension of the pelvic colon by inflating a balloon in the irritable colon syndrome. Gut inflating a balloon in

14 Swarbrich ET, Bat L, Hegorty JE, Williams CB. Site of pain from the irritable bowel. Lancet 1980; ii: 443-6.

15 Whitehead WE, Holtkotter B, Enck P, Hoelzl R, Holmes KO, Anthony $\mathrm{J}$, et al. Tolerance for rectosigmoid distension in irritable bowel syndrome. Gastroenterology 1990; 98: 1187-92.

16 Ritchie J. Mechanisms of pain in irritable bowel syndrome. In: Read NW, ed. Irritable bowel syndrome. Philadelphia, Grune and Stratton, 1985: 163-72.

17 Dawson AM. Origin of pain in the irritable bowel syndrome. In: Read NW, ed. Irritable bowel syndrome. Philadelphia: In: Read NW, ed. Irritable bowel sym

18 Bradette M, Delvaux M, Staumont G, FioramontiJ, BuénoL, Frexinos J. Evaluation of colonic sensory thresholds in IBS patients using a barostat: definition of optimal conditions and comparison with healthy subjects. Dig Dis Sci 1994; 39: 449-57.

19 Mayer EA, Gebhart GF. Functional bowel disorders and the visceral hyperalgesia hypothesis. In: Mayer EA, Raybould HE, eds. Basic and clinical aspects of chronic abdominal pain. New York: Elsevier, 1993: 3-28.

20 Bradette M, Staumont G, Delvaux M, FioramontiJ, BuénoL, Frexinos J. Octreotide increases thresholds of colonic visceral perception in IBS patients without modifying muscle tone. Dig Dis Sci 1994; 39: 1171-8.

21 Sofroniew MV, Weindl A. Central nervous system distribution of vasopressin, oxytocin and neurophysin. In: bution of vasopressin, oxytocin and neurophysin. In: Martinez JL, Jensen RA, Messing RB, Rigter $\mathrm{H}$, memory processes. New York: Academic Press, 1981: 327-69.

22 Lundeberg T, Meister B, Björkstrand E, Uvnäs-Moberg K. Oxytocin modulates the effects of galanin in carrageenan-
induced hyperalgesia in rats. Brain Res $1993 ; 608: 181-5$.

23 Kordower JH, Bodnar RJ. Vasopressin analgesia: specificity of action and non-opioid effects. Peptides 1984; 5: 747-56.

24 Sofroniew MV. Vasopressin, oxytocin and their related neurophysins. In: Björklund A, Hökfelt $\mathrm{T}$, eds. $G A B A$ and neuropeptides in the $C N S$, part 1 . Amsterdam: Elsevier, 1985: $93-165$.

25 Madrazo I, Franco-Bourland RE, Léon-Meza VM, Mena I. Intraventricular somatostatin-14, arginin vasopressin and oxytocin: analgesic effect in a patient with intractable cancer pain. $\mathcal{F}$ Appl Neurophysiol 1987; 50: 427-31.

26 Thompson WS, Dotterval G, Drossman DA, Heaton KW, Kruis SW. Irritable bowel syndrome: guidelines for the diagnosis. Gastroenterol Int 1989; 2: 92-5.

27 Hachet T, Caussette M. A multifunction and proorammable computerized barostat. Gastroenterol Clin Biol 1993; 17: 347-51.
28 Willer JC. Comparative study of perceived pain and nociceptive flexion reflex in man. Pain 1977; $3: 69-80$

29 Willer JC, Boureau F, Albe-Fessard D. Supraspinal influences on nociceptive flexion reflex and pain sensation in man Brain Res 1979; 179: 61-8.

30 Willer JC, Roby A, Le Bars D. Psychophysical and electrophysiological approaches to the pain-relieving effects of heterotopic nociceptive stimuli. Brain 1984; 107: 1095-112.

31 Hasler W, Soudah H, Owyang C. Somatostatin analog inhibits sensory afferent response to rectal distension in irritable bowel patients with rectal urgency, Gastroenterology 1992; 102: 457.

32 Delvaux M, Louvel D, Scherrer B, Fraitag B, Frexinos J. The $\mathrm{K}$-agonist fedotozine increases thresholds of first sensation and pain perception to colonic distension in patients with irritable bowel syndrome. Gastroenterology 1995; 108: A590.

33 Prior A, Read N. Reduction of rectal sensitivity and postprandial motility by granisetron, a 5-HT3 receptor antagonist, in patients with irritable bowel syndrome. Aliment Pharmacol Ther 1993; 7: 175-80.

34 von der Ohe MR, Camilleri M, Kvols LK. A 5-HT 3 antagonist corrects the post-prandial colonic hypertonic response in carcinoid diarrhea. Gastroenterology 1994, 106: 1184-9.

35 Helmreich DL, Thiels E, Sved AF, Verbalis JG, Stricker EM. Effect of suckling on gastric motility in lactating rats. $\mathrm{Am}$ fPhysiol 1991; 261: R38-43.

36 Rogers RC, Hermann GE. Oxytocin, oxytocin antagonist, TRH and hypothalamic paraventricular nucleus stimulation effects on gastric motility. Peptides 1987; 8: lation effec

37 Millan MJ, Schmauss C, Millan MH, Herz A. Vasopression and oxytocin in the rat spinal cord: analysis of their role in the control of nociception. Brain Res 1984; 309, 384-8.

38 Berntson GG, Berson BS. Antinociceptive effects of intraventricular or systemic administration of vasopressin in the rat. Life Sci 1980; 26: 455-9.

39 Arletti R, Benelli A, Bertolini A. Influence of oxytocin on nociception and morphine antinociception. Neuropeptides 1993; 24: 125-9.

40 Kovacs GL, Sarnyai Z, Izbeki F, Szabo G, Telegdy G, Barth T, et al. Effects of oxytocin-related peptides on acute morphine tolerance: opposite actions by oxytocin and its phine tolerance: opposite actions by oxytocin and its receptor

41 Yamazoe $M$, Shiosaka S, Shibasaki T, Ling N, Tateishi K, Hashimura E, et al. Neuroscience 1984; 13: 1243-66.

42 Cook IJ, Van Eeden A, Collins SM. Patients with irritable bowel syndrome have greater pain tolerance than normal subjects. Gastroenterology 1987; 93: 727-33.

43 Kovacs GL, Horvath ZS, Sarnyai Z, Faludi M, Telegdy G. Oxytocin and a C-terminal derivate (Z-prolyl-D-leucine) attenuate tolerance to and dependence on morphine and interact with dopa mouse brain. Neuropharmacology 1985; 24: 413-9.

44 Kovacs GL, Sarnyai Z, Szabo G, Telegdy G. Development of morphine tolerance is under tonic control of the brain of morphine tolerance is under tonic control of the

45 Mathias JR, Clench MH, Reeves-Darby VG et al. Effect of leuprolide acetate in patients with moderate to severe functional bowel disease. Double-blind, placebocontrolled study. Dig Dis Sci 1994; 39: 1155-62.

46 Mathias JR, Clench MH, Roberts PH, Reeves-Darby VG Effect of leuprolide acetate in patients with functiona bowel disease long-term follow-up after double-blind, placebo-controlled study. Dig Dis Sci 1994; 39: 1163-70. 